Neal, T.M.S. (2017). Identifying the forensic psychologist role. In G. Pirelli, R. Beattey, \& P. Zapf (Eds.), The ethical practice of forensic psychology: A casebook (pp. 1-17). Hoboken, NJ: Wiley.

This is a pre-print version of chapter cited above. It is not the publication of record. Please see the Wiley book or the individual chapter through the Wiley website for the final version of record:

https://global.oup.com/academic/product/the-ethical-practice-of-forensic-psychology$9780190258542 ? \mathrm{cc}=\mathrm{us} \&$ lang $=\mathrm{en} \&$ 
Chapter 1: Identifying the Forensic Psychologist Role

Tess M.S. Neal

Arizona State University

Author Note

Tess M.S. Neal, New College of Interdisciplinary Arts \& Sciences, Arizona State University.

The author was supported in part by an NSF Interdisciplinary Postdoctoral Fellowship (SES1228559) during the writing of this chapter. Any opinions, findings, conclusions, or recommendations expressed in this chapter are those of the author and does not necessarily reflect those of NSF.

Correspondence concerning this chapter should be addressed to Tess M.S. Neal, New College of Interdisciplinary Arts \& Sciences - SBS, Arizona State University, 4701 West Thunderbird Rd, Glendale AZ 85306. E-mail: Tess.Neal @asu.edu

Appeared in:

Neal, T.M.S. (2017). Identifying the forensic psychologist role. In G. Pirelli, R. Beattey, \& P. Zapf (Eds.), The ethical practice of forensic psychology: A casebook. Hoboken, NJ: Wiley. 


\begin{abstract}
Since its debut over a century ago, forensic psychology has matured into a formally recognized specialty area of psychology with its own set of ethical guidelines; however, a consensual definition of forensic psychology remains elusive. After describing the field's historical and current struggles to define itself, two ethical issues are discussed that are especially applicable to psychology in legal contexts. The first is the critical differences between serving in therapeutic versus forensic roles and the associated ethical obligation to refrain from serving in both roles in the same case. Despite the terminology used in the literature, treatment in forensic contexts can be ethically appropriate. This chapter considers the current state of the literature regarding treatment in forensic contexts and suggests that this is likely to be an area of future growth for the field. The second ethical issue discussed in this chapter is the insidious effect of the adversarial process on psychologists' objectivity in forensic contexts, termed "forensic identification" or "adversarial allegiance." The forensic ethical guidelines affirm the primacy of this issue in forensic contexts, as evidenced by addressing it in the first two published guidelines. However, field and experimental evidence suggest psychologists have a challenging (if not impossible) task in avoiding partiality in adversarial forensic contexts. The chapter ends by briefly considering the methods psychologist might use in an effort to reduce partiality and by recognizing more research is needed to identify what else psychologists can do to strive to uphold the ethical guidelines in this regard.
\end{abstract}




\section{Chapter 1: Identifying the Forensic Psychologist Role}

The history of forensic psychology dates back to the beginning of the twentieth century, with Sigmund Freud lecturing judges on the practicality of psychology in 1906, Hugo Muensterberg applying psychological principles to legal problems in his book On the Witness Stand in 1908, and William Healy establishing the first psychological clinic attached to a court in Chicago in 1909 (Tapp, 1976). The first published case in which a psychologist testified as an expert witness in a U.S. case was in State v. Driver in 1921, though it wasn't until the 1940s and 1950s - and especially after the watershed Jenkins v. U.S. case in 1962 in which psychologists were deemed suitable experts to testify about mental illness (rather than exclusively medicallytrained experts) - that psychologists began testifying as experts in court more regularly (Bartol \& Bartol, 2014).

In 1975, the American Psychological Association (APA) commissioned a task force to consider the ethical issues involved when psychologists interacted with the criminal justice system. The task force's report was published five years later, presenting 12 recommendations that psychology as a profession should set for the ethical service of psychologists in criminal justice settings (Task Force on the Role of Psychology in the Criminal Justice System, 1980). About a decade later, the first Specialty Guidelines for Forensic Psychologists were published by the American Academy of Forensic Psychology and the American Psychology-Law Society (Committee on Specialty Guidelines for Forensic Psychologists, 1991; updated and published by APA in 2013) and the 1992 revision of the APA Ethical Principles and Code of Conduct for Psychologists added a new section on "Forensic Activities" for the first time (APA, 1992). And in 2001, the APA formally recognized forensic psychology as a specialty area of psychology. 
The specialty area recognition was renewed by APA in 2008, and a petition is currently making its way through APA governance again for a 2015 renewal.

\section{Defining Forensic Psychology}

Throughout these various historical markers in the history of forensic psychology, the definition of "forensic psychology" has not always been consistent. In fact, even today the definition of forensic psychology is a matter of some debate. Take, for example, APA's definition of forensic psychology as a specialty area of psychology: "the professional practice by psychologists within the areas of clinical psychology, counseling psychology, school psychology, or another specialty recognized by the American Psychological Association, when they are engaged as experts and represent themselves as such, in an activity primarily intended to provide professional psychological expertise to the judicial system" (APA, 2015, para 1., emphasis added). In this definition, the APA suggests that a forensic psychologist is a particular kind of professional psychologist - one that practices applied professional psychology and that selfidentifies as a "forensic" practitioner.

In contrast, the Specialty Guidelines for Forensic Psychology (APA, 2013) make clear that any psychologist - whether or not formally trained as a "forensic" psychologist or trained professionally at all (e.g., an experimental psychologist not trained in clinical, counseling, school, or another professional APA designation) - can apply psychology to the law and function in a forensic psychological capacity so long as they practice within the bounds of their expertise. Specifically, the Specialty Guidelines define forensic psychology as the "professional practice by any psychologist working within any subdiscipline of psychology (e.g., clinical, developmental, social, cognitive) when applying the scientific, technical, or specialized knowledge of psychology to the law to assist in addressing legal, contractual, and administrative matters...[which] does not 
depend on the practitioner's typical areas of practice or expertise, but rather on the service provided in the case at hand" (p. 7, emphasis added).

Brigham (1999) provided a historical perspective regarding the debated definition of "forensic psychology" in the context of the initial application to have forensic psychology designated as a specialty area of psychology by APA. The petition was initiated as a joint effort led by the American Psychology-Law Society and the American Academy of Forensic Psychology, but the cooperative effort between the two organizations was eventually abandoned due to disagreements about the definition of forensic psychology (Otto \& Ogloff, 2014).

Brigham discussed how the two organization's conceptualizations of forensic psychology varied from a broad focus on psychology-law interactions generally versus a more narrow focus on clinical applications to the legal system. The breadth of the definition carried implications - on the positive side with regard to promoting growth and coherence in the field, but on the negative side problems associated with grouping clinical ${ }^{1}$ psychologists with nonclinicians (e.g., social, cognitive, developmental psychologists), given different training and licensure requirements. After nearly four years of vigorous debate about the nature and definition of forensic psychology, it was ultimately decided that the American Academy of Forensic Psychology would move forward with the petition without further involvement from the American Psychology-Law Society, and that the petition would define forensic psychology narrowly by focusing on the primarily clinical aspects of psychology and law (Otto \& Heilbrun, 2002).

The differences in the definition of forensic psychology observed by Brigham in 1999 continue today, as mirrored the current broad definition of forensic psychology seen in the Specialty Guidelines (APA, 2013) and the narrow APA specialty definition. In fact, Otto and

\footnotetext{
${ }^{1}$ The term "clinical" is used as an umbrella term encompassing clinical, counseling, school, and other psychological specialties recognized by the APA.
} 
Ogloff (2014) assert in their chapter focused on defining forensic psychology that "THERE IS NO CONSENSUAL DEFINITION OF FORENSIC PSYCHOLOGY" (p. 35, emphasis in original). Otto and Heilbrun (2002) reflected after the debate regarding the forensic specialization petition that "the area of law and psychology is unusual, if not unique, in the combination of areas of psychology that psychologists attracted to the application of their research and practice in legal contexts embrace: Preserving the combination of these areas is quite important to the larger field" (p. 8). Thus, the revision of the Specialty Guidelines explicitly attempted to embrace the combination of various ways in which people can practice forensic psychology by adopting the broad definition of forensic psychology and by titling the guidelines for "forensic psychology" rather than "psychologists" as the 1991 version did (because the 2013 revision defines forensic psychology with regards to the service at hand rather than a particular professional identity).

Although much of the current chapter - and likely, the book itself given the chapter lineup - will focus largely on the clinical aspects of psychology and law, this chapter relies on the broader definition of forensic psychology provided by the Specialty Guidelines (APA, 2013). An important element of the Specialty Guidelines' definition of forensic psychology is that psychological services are not automatically "forensic" just because the service takes place in, or the product is presented in, a legal forum. For instance, a psychologist subpoenaed to testify in court about a previous psychotherapy case or clinical assessment case or a previous research finding is not necessarily practicing forensically, nor is a psychologist who begins treatment with a court-ordered client. These kinds of activities become forensic "from the time the practitioner reasonably expects to, agrees to, or is legally mandated to provide expertise on an explicitly psycholegal issue" (p. 7). The time at which a psychologist agrees to or is mandated to address 
an explicitly psycholegal issue is thus a critical time-point; one in which the forensically-relevant ethical standards and guidelines attach and begin to apply (see Specialty Guidelines for Forensic Psychology 4.02.02 and 4.02.03 for further discussion).

Ethical standards relevant to the forensic psychologist role. Two primary sources of ethical standards and guidelines govern forensic psychologists' work. The first is the overarching Ethical Principles of Psychologists and Code of Conduct broadly applicable to psychologists practicing in many different psychological capacities and settings (hereinafter referred to as the EPPCC; APA, 2010). The second is the Specialty Guidelines for Forensic Psychology (APA, 2013), which were developed to complement the EPPCC and provide additional guidance for psychologists practicing in forensic areas. The forensic specialty guidelines are unique in that they are the only APA-approved guidelines that address a complete specialty practice area and are broader in scope than any other APA-developed guidelines.

Two additional relevant sets of ethical standards are the Standards for Psychological Services in Jails, Prisons, Correctional Facilities, and Agencies published by the International Association for Correctional and Forensic Psychology (Formerly American Association for Correctional Psychology; IACFP, 2010) and the American Bar Association Criminal Justice Mental Health Standards (CJMHS standards; ABA, 1986). Although the IACFP standards address psychological assessment and treatment services in forensic and correctional settings, their primary purpose is to inform pre-and post-adjudication psychological services that are independent of the psycholegal question in the case at hand. By focusing mostly on services independent of the immediate psycholegal question, these guidelines are more "correctional" than "forensic," as forensic is defined by the Specialty Guidelines for Forensic Psychology (APA, 2013), and thus the IACFP standards will not be covered in depth in this chapter. 
The American Bar Association CJMHS standards (ABA, 1986) were developed to guide the cooperation among legal and mental health professionals and to establish a basic framework for educating legal and mental health professionals about the intersection between the law and mental health issues. These ABA standards are certainly applicable to this chapter - for instance, the guidelines in part I of the standards delineate and outline the primary responsibilities of mental health professionals in four specific roles in the criminal process scientific, evaluative, consultative, and therapeutic (Standard 7-1.1), and this particular standard also makes clear that mental health professionals must be objective and impartial in their work in the criminal process rather than adopting an adversarial perspective. However, because these standards are intended to guide the interaction between legal and mental health professionals, and because they refer legal and mental health professionals to their respective profession's ethical standards to guide their behavior, the ABA Criminal Justice Mental Health Standards will not be covered in depth in this chapter.

The key ethical issue with regard to forensic psychological work - regardless of whether the broad or narrow definition of forensic psychology is adopted - is that psychologists must practice within the bounds of their expertise. In Standard 2, "Competence," the EPPCC (APA, 2010) lays out guidelines for psychologists' involvement in clinical services, teaching, research, and consulting, making clear that psychologists must already have or else develop appropriate expertise before doing the work. Specifically, EPPCC standard 2.01, "Boundaries of Competence" reads:

- 2.01 (a), "Psychologists provide services, teach, and conduct research with populations and in areas only within the boundaries of their competence, based on their education, training, supervised experience, consultation, study, or professional experience. And 
- 2.01 (c) Psychologists planning to provide services, teach, or conduct research involving populations, areas, techniques, or technologies new to them undertake relevant education, training, supervised experience, consultation, or study.

Similar but somewhat more detailed standard can be found in the Specialty Guidelines for Forensic Psychology (APA, 2013). Specifically,

- 2.01 Scope of Competence, "When determining one's competence to provide services in a particular matter, forensic practitioners may consider a variety of factors including the relative complexity and specialized nature of the service, relevant training and experience, the preparation and study they are able to devote to the matter, and the opportunity for consultation subject matter in question. Even with regard to subjects in which they are expert, forensic practitioners may choose to consult with colleagues.

- 2.02 Gaining and Maintaining Competence, "Competence can be acquired through various combinations of education, training, supervised experience, consultation, study, and professional experience. Forensic practitioners planning to provide services, teach, or conduct research involving populations, areas, techniques, or technologies that are new to them are encouraged to undertake relevant education, training, supervised experience, consultation, or study. Forensic practitioners make ongoing efforts to develop and maintain their competencies (EPPCC Standard 2.03). To maintain the requisite knowledge and skill, forensic practitioners keep abreast of developments in the fields of psychology and the law.”

Thus, psychologists who expect to, agree to, or are legally mandated to provide expertise on psycholegal issues (i.e., will conduct forensic psychological activities) must have the appropriate training, education, or experience to do so before engaging in the work. If they do 
not already have the appropriate competencies, they must seek and develop the expertise before engaging in the activities. Furthermore, the EPPCC (APA, 2010) requires that psychologists engaging in forensic activities learn how the legal system defines the role of the psychologist (Standard 2.01[f]), and the Specialty Guidelines for Forensic Psychology require forensic practitioners to develop a reasonable understanding of the legal system and individual's legal rights before engaging in forensic work (2.04, "Knowledge of the Legal System and the Legal Rights of Individuals").

The onus is thus on psychologists acting in forensic roles to recognize that there are unique competencies that the psychologist must have in order to ethically fulfill the role of a forensic psychologist, and to make sure they develop those competencies and understand their role in the legal system according to the legal system's rules before engaging in forensic psychological activities. We now turn to describing the differences in the roles of traditional clinical psychology versus forensic-clinical psychology.

\section{Therapeutic versus Forensic Roles}

Both the general psychology ethics code and the forensic-specific ethics code prohibited the mixing of therapeutic and forensic roles since the early 1990s (see e.g. Guideline IV-D, Committee on Ethical Guidelines for Forensic Psychologists, 1991 and Standard 7.03 of the APA EPPCC, 1992); however, despite the ethics code admonitions, various sources commented on the number of mental health professionals serving in both therapeutic and forensic roles in the same case throughout the 1990s (see e.g., Greenberg \& Shuman, 1997; Strasburger, Gutheil, \& Brodsky, 1997). Many of these professionals were likely responding to market pressures, during a time in which managed care sharply curtailed payment for long-term therapy provision and both the legal system and most mental health professionals saw efficiency (in time and money) 
in having a therapist who already knew the patient well serve as an expert witness about psycholegal issues involving that patient (Greenberg \& Shuman, 1997; Strasburger et al., 1997). The ethics codes prohibited the mixing of roles, but did not explain how or why those different roles should be kept separate and many mental health and legal professionals did not yet understand the importance of separating the roles.

In 1997, two seminal articles were published that addressed and described in detail the conflicting and problematic role differences between forensic and therapeutic service provision, concluding that therapeutic and forensic roles were mutually exclusive and irreconcilable when provided in the same case. These two articles were similar in content and were published nearly simultaneously, but without any collaboration between the various authors and in two different fields of mental health (Greenberg \& Shuman, 2007). Greenberg and Shuman (1997) published "Irreconcilable Conflict between Therapeutic and Forensic Roles" in Professional Psychology: Research and Practice and Strasburger, Gutheil, and Brodsky (1997) won the Guttmacher Award for Outstanding Contribution to the Literature on Forensic Psychiatry for "On Wearing Two Hats: Role Conflict in Serving as Both Psychotherapist and Expert Witness," published in the American Journal of Psychiatry.

Please refer to Table 1 for Greenberg and Shuman's (1997) 10 principles that differentiate the roles of forensic and therapeutic services - principles that were echoed in Strasburger et al.'s (1997) paper. These papers clarified the ethical problems associated with serving in the dual forensic-therapeutic role for the mental health professions and each has been influential in their respective fields. Both papers state that the courts may not necessarily understand the mental health professional's ethical duty to resist the dual role, but suggest that 
cross-examination focused on the ethical problems associated with the dual role would serve as

an effective basis for impeaching the credibility of a dual-role expert.

Table 1.

Ten Differences between Therapeutic and Forensic Relationships

\begin{tabular}{lll}
\hline & \multicolumn{1}{c}{ Care Provision } & \multicolumn{1}{c}{ Forensic Evaluation } \\
\hline $\begin{array}{l}\text { Whose client is } \\
\text { patient/litigant? }\end{array}$ & The mental health practitioner & The attorney \\
$\begin{array}{l}\text { 2. The relational privilege that } \\
\text { governs disclosure in each }\end{array}$ & Therapist-patient privilege & $\begin{array}{l}\text { Attorney-client and attorney work- } \\
\text { product privilege }\end{array}$
\end{tabular}
relationship

3. The cognitive set and evaluative attitude of each

Supportive, accepting, empathic Neutral, objective, detached expert

4. The differing areas of competency of each expert

Therapy techniques for treatment of the impairment

Diagnostic criteria for the purpose of therapy

Mostly based on information from the person being treated with little scrutiny of that information by the therapist

Patient structured and relatively less structured than forensic evaluation

8. The nature and degree of "adversarialness" in each relationship

9. The goal of the professional in each relationship

10. The impact on each relationship of critical judgment by the expert

\begin{abstract}
A helping relationship; rarely adversarial
\end{abstract}

Therapist attempts to benefit the patient by working within the therapeutic relationship

The basis of the relationship is the therapeutic alliance and critical judgment is likely to impair that alliance
Forensic evaluation techniques relevant to the legal claim

Psycholegal criteria for purpose of legal adjudication

Litigant information supplemented with that of collateral sources and scrutinized by the evaluator and the court

Evaluator structured and relatively more structured than therapy

An evaluative relationship; frequently adversarial

Evaluator advocates for the results and implications of the evaluation for the benefit of the court

The basis of the relationship is evaluative and critical judgment is unlikely to cause serious emotional harm

Table republished from Stuart A. Greenberg \& Daniel W. Shuman, Irreconcilable conflict between therapeutic and forensic roles. Professional Psychology: Research and Practice, 28(1), 50-57. (1997). Published by the American Psychological Association, Inc. doi: 10.1037/07357028.28.1.50. Reprinted with permission. 
As evidenced in Table 1, various ethical standards and guidelines apply to the issue of dual roles in therapeutic and forensic contexts. Three primary ethical issues will be discussed here as they apply to the dual-role question, including ethical standards and existing case law regarding multiple relationships, confidentiality, and informed consent. These three ethical issues largely map onto three of the principles in Table 1. Specifically, ethical guidelines regarding multiple relationships largely deal with defining "who is the client," as identified in principle one. Issues of confidentiality and disclosures of information are highlighted by principle two and are guided by both ethical standards and case law. Finally, principle nine indicates that the mental health professional's goal is different in therapeutic and forensic contexts, and ethical guidelines and case law make clear that the mental health professional must provide information about the purpose of the mental health service and intended uses of the information and obtain informed consent (or assent) - and that the informed consent process looks different in therapeutic and forensic roles.

Both the EPPCC (APA, 2010) and the Specialty Guideline for Forensic Psychology (APA, 2013) prohibit multiple relationships. EPPCC Standard 3.05, "Multiple Relationships" and specialty forensic guideline 4.02 "Multiple Relationships" define a multiple relationship as a practitioner being in a professional role with a person as well as a personal, financial, or other relationship with the same person, a person closely related to the person, or an adverse party to that person. They go on to describe the conflicts of interest inherent in having multiple relationships with a recipient of professional services and to prohibit becoming involved in such multiple relationships (see also EPPCC standard 3.06, "Conflict of Interest" and specialty forensic guideline 1.03, "Avoiding Conflicts of Interest”). In addition, they describe the unique ethical challenges associated with identifying the client and the purpose of the service(s), 
particularly when one of the services is requested by a third-party (see EPPIC Standard 3.07, “Third-Party Requests for Services"). Perhaps the most relevant details are provided in the specialty forensic guidelines:

- 4.02.01 Therapeutic-Forensic Role Conflicts, "Providing forensic and therapeutic psychological services to the same individual or closely related individuals involves multiple relationships that may impair objectivity and/or cause exploitation or other harm. Therefore, when requested or ordered to provide either concurrent or sequential forensic and therapeutic services, forensic practitioners are encouraged to disclose the potential risk and make reasonable efforts to refer the request to another qualified provider. If referral is not possible, the forensic practitioner is encouraged to consider the risks and benefits to all parties and to the legal system or entity likely to be impacted, the possibility of separating each service widely in time, seeking judicial review and direction, and consulting with knowledgeable colleagues. When providing both forensic and therapeutic services, forensic practitioners seek to minimize the potential negative effects of this circumstance (EPPCC Standard 3.05).”

Questions of confidentiality and appropriate disclosures of information go hand-in-hand with questions about identifying the client. Table 1 shows that the therapist-patient privilege governs the disclosure of confidential information in the therapeutic context (where the recipient of services is the client), and that attorney-client and attorney work-product privilege govern disclosure in the forensic evaluation context (where the attorney or court is the client rather than the evaluee). The United States Supreme Court affirmed psychotherapeutic confidentiality as a vital interest of society by recognizing the psychotherapist privilege in Jaffee v. Redmond (1996), recognizing the psychotherapy client's right to govern whether and how his or her 
information is disclosed in most circumstances. However, this privilege does not apply to forensic evaluation contexts, where instead the attorney may decide how and whether to disclose the information rather than the evaluee him- or herself.

Regardless of whether the disclosure privilege is governed by a client in a therapeutic context or by an attorney in a forensic context, the mental health professional is ethically obligated to keep information confidential until they are permitted or required to disclose the information (EPPCC 4.01, "Maintaining Confidentiality" and 4.05, "Disclosures"). Psychologists must discuss these limitations on the requirements of confidentiality and the permitted and required circumstances of disclosing information prior to and throughout the service provision process in both therapeutic and forensic contexts (EPPCC 4.02, "Discussing the Limits of Confidentiality" and specialty forensic guideline 6.03, "Communication with Forensic Examinees"). Specifically, guideline 6.03 of the Specialty Guidelines for Forensic Psychology (APA, 2013) reads:

- 6.03 Communication with Forensic Examinees, "Forensic practitioners inform examinees about the nature and purpose of the examination (EPPCC Standard 9.03). Such information may include the purpose, nature, and anticipated use of the examination; who will have access to the information; associated limitations on privacy, confidentiality, and privilege including who is authorized to release or access the information contained in the forensic practitioner's records; the voluntary or involuntary nature of participation, including potential consequences of participation or nonparticipation, if known; and, if the cost of the service is the responsibility of the examinee, the anticipated cost." As made clear above in guideline, psychologists must not only inform evaluees in forensic contexts with information about the limits of confidentiality, but must also provide 
information about the purpose and nature of the evaluation. This is also a legal requirement, as the United States Supreme Court held in Estelle v. Smith (1981) that defendants in forensic contexts (and their legal counsel) have the right to be informed of the nature and purpose of pretrial mental health examinations and the intended uses of the information obtained in the evaluation prior to the start of the examination.

Psychologists must provide information about the nature and purpose of a psychological service and then seek informed consent or assent depending on the context. Informed consent must be sought from evaluees who are not court-ordered to undergo examination before proceeding with the evaluation and then again as indicated throughout the evaluation process (Guideline 6.03.01, "Persons Not Ordered or Mandated to Undergo Examination;" see also EPPCC Standard 3.10, "Informed Consent"). In contrast, forensic specialty Guideline 6.03.02, "Persons Ordered or Mandated to Undergo Examination or Treatment" states that psychologists should seek the informed assent of the person, but does not require that consent be provided before proceeding in court-ordered forensic contexts (see also EPPCC Standard 3.10, "Informed Consent"). Finally, guidance is provided for protecting the rights and welfare of people whose ability to understand and consent or assent to the process in both therapeutic and forensic contexts (see specialty forensic guideline 6.03.03, "Persons Lacking Capacity to Provide Informed Consent," and EPPCC Standard 3.10, "Informed Consent").

Is it unethical to provide treatment in forensic contexts? The preceding discussion of "therapeutic" versus "forensic" roles makes it sound as if there is a role for treatment in nonforensic contexts and for assessment in forensic contexts, but perhaps not for ethical treatment in forensic contexts. Both Greenberg and Shuman (1997) and Strasburger et al. (1997) mention clinical assessment and indicate that psychological evaluations can be used in a "therapeutic" 
context to inform treatment, but neither source discusses the potential role of treatment in forensic contexts. However, the Specialty Guidelines for Forensic Psychology (APA, 2013) allow for a role for treatment in forensic psychology. Specifically:

- 4.02.03 Provision of Forensic Therapeutic Services, "Although some therapeutic services can be considered forensic in nature, the fact that therapeutic services are ordered by the court does not necessarily make them forensic. In determining whether a therapeutic service should be considered the practice of forensic psychology, psychologists are encouraged to consider the potential impact of the legal context on treatment, the potential for treatment to impact the psycholegal issues involved in the case, and whether another reasonable psychologist in a similar position would consider the service to be forensic and these Guidelines to be applicable. Therapeutic services can have significant effects on current or future legal proceedings" (see also Guideline 6.03.02, Persons Ordered or Mandated to Undergo Examination or Treatment, emphasis added). What might forensic treatment services look like? Recall the definition of when an activity is "forensic" as identified in the Specialty Guidelines for Forensic Psychology (APA, 2013); "from the time the practitioner reasonably expects to, agrees to, or is legally mandated to provide expertise on an explicitly psycholegal issue" (p. 7). Therefore, a treatment service might be considered "forensic" when the treatment is explicitly designed to or the practitioner agrees to take the case in order to impact the psycholegal issue(s) in the case at hand. Take for example, psychoeducational treatment to restore (or establish) competency to stand trial - a treatment service designed to directly impact the psycholegal issue, and a service clearly "forensic" from the outset (as per the various definitions above). For further discussion of these issues, please see Neal \& Zelle (in preparation) for an in-depth discussion of treatment in forensic contexts, 
including the special ethical challenges of forensic treatment, and see also Zelle \& Neal (in preparation) for an analysis of the unique ethical issues applicable to adjudicative competency restoration services. An important note is that even though forensic treatment may be an ethically appropriate service that practitioners may provide, the role separation between therapeutic and forensic contexts within a single case discussed above remains applicable.

\section{Forensic Identification (a.k.a. Adversarial Allegiance) and Objectivity}

Both the EPPCC (APA, 2010) and the Specialty Guidelines for Forensic Psychology (APA, 2013) stress the importance of accuracy, honesty, and fairness in the practice, science, and teaching of psychology. However, the two sources treat this issue differently. Unlike the ethical issues discussed in this chapter so far, the EPPCC has no ethical standards that bear directly on this issue in the code of conduct - rather, the attention paid to this issue is present primarily in one of the five aspirational principles that precede the code of conduct (EPPCC Principle C: Integrity). In contrast, the Specialty Guidelines for Forensic Psychology highlight the importance of and relevance of this issue in forensic contexts by providing guidance on this issue in the first two guidelines, prioritizing them before any other ethical guidelines relevant to forensic psychology. Specifically,

- 1.01 Integrity, "Forensic practitioners strive for accuracy, honesty, and truthfulness in the science, teaching, and practice of forensic psychology and they strive to resist partisan pressures to provide services in any ways that might tend to be misleading or inaccurate."

- 1.02 Impartiality and Fairness, "When offering expert opinion to be relied upon by a decision maker, providing forensic therapeutic services, or teaching or conducting research, forensic practitioners strive for accuracy, impartiality, fairness, and independence. Forensic practitioners recognize the adversarial nature of the legal system 
and strive to treat all participants and weigh all data, opinions, and rival hypotheses impartially. When conducting forensic examinations, forensic practitioners strive to be unbiased and impartial, and avoid partisan presentation of unrepresentative, incomplete, or inaccurate evidence that might mislead finders of fact..."

In addition to the two guidelines above, Guidelines 11.01 "Accuracy, Fairness, and Avoidance of Deception" and 11.04 "Comprehensive and Accurate Presentation of Opinions in Reports and Testimony" bear on the issue of unbiased communication in reports and testimony, and Guideline 5.02 "Fee Arrangements" addresses the biasing effects of adversarial (and particularly contingency) payment arrangements.

The unique attention paid to these issues in the Specialty Guidelines for Forensic Psychology (APA, 2013) is warranted based on findings demonstrating the biasing effects of the adversarial legal system on objective psychological practice. Forensic identification was defined by Zusman and Simon (1983) as "the subtle influence of adversarial proceedings on initially neutral witnesses" (p. 1300), such that forensic evaluators unintentionally adopt the viewpoint of the retaining attorney. Zusman and Simon examined the mental health examinations of 42 litigants in a lawsuit resulting from the collapse of a coal slag heap in West Virginia in 1972. They compared the evaluations conducted by plaintiff and defense experts, finding systematic differences in the experts' evaluation conclusions that were consistent with the retaining party's positions. They stated forensic identification occurs "when psychiatric expert witnesses become involved in a case about which they are initially neutral. Through frequent contact with the litigants or their attorneys, the experts become involved with a viewpoint to the extent that their examination techniques and evaluation approaches are subtly influenced. Without intending to or even being aware of it, they tend to emphasize findings and patterns that support 'their side"' (p. 
1304). The forensic identification finding by mental health professionals in adversarial forensic settings has been observed by other investigators as well, including in several recent field studies - despite the ethical guidelines about striving to be unbiased and impartial (e.g., DeMatteo, Edens, Galloway, Cox, Toney Smith, \& Formon, 2014; Lloyd, Clark, \& Forth, 2010; Murrie, Boccaccini, Johnson, \& Janke, 2008; Murrie, Boccaccini, Turner, Meeks, Woods, \& Tussey, 2009; Otto, 1989).

An important experimental study investigating the causal link between adversarial referral party and forensic identification, or "adversarial allegiance" as these particular researchers called the phenomenon (Murrie, Boccaccini, Guarnera, \& Rufino, 2013), was recently published in Psychological Science, the leading peer-reviewed journal of empirical research in psychology. This study is important because it experimentally manipulated the referral source (defense or prosecuting attorney) but kept all other study information constant, and it randomly assigned participants to one condition or the other. These two features of the study allow causal inference to be drawn from the manipulation because nothing varied systematically between the two groups except for the referral source, so any differences observed on the dependent variables would be attributable to the manipulation. Furthermore, this study had good ecological validity, meaning that the participants were actual forensic mental health professionals who were led to believe they were conducting a real file review rather than participating in a research study.

This experimental study did indeed find differences on the dependent variables, which were scores on two different commonly-used, well-researched risk assessment tools. Results indicated that psychologists who believed they were working for the prosecution assigned higher risk scores to offenders, whereas psychologists who believed they were working for the defense 
assigned lower risk scores to the same offenders (Murrie et al., 2013). Because the only thing that differed between the groups was for whom the psychologists believed they were working, and all other potentially explanatory variables had been evenly distributed between the groups or controlled for, the result can be attributed to the "adversarial allegiance effect," or the tendency for neutral evaluators to interpret case information in ways that the adversarial retaining party would prefer.

One last important finding from the Murrie et al. (2013) study speaks to what forensic evaluators might do to try to manage the effects of forensic identification in light of our ethical obligations to strive for objectivity. The relevant finding was that although both of the risk assessment tools were standardized psychological tools, one required somewhat more subjectivity in scoring the items than the other. The effect sizes for the more subjective tool were large, whereas the effect sizes for the more objective tool were small-to-medium (Murrie et al., 2013). These findings suggest that although standardized assessment tools do not eliminate adversarial allegiance in forensic settings, the more objective the tool, the lower the effect of adversarial allegiance. Other strategies psychologists might consider for reducing bias in their forensic work include setting out to disconfirm rather than confirm their hypotheses, "considering the opposite" of their current thought patterns and hypotheses to generate ideas for attempting to disconfirm their hypotheses, and perhaps seeking to be court-appointed rather than being hired by one of the adversarial referral parties (see Neal \& Brodsky, under review for further discussion of biasing factors in forensic contexts and potential bias-correction strategies).

\section{Summary and Conclusions}

This chapter traced the history of forensic psychology back to the beginning of the twentieth century, highlighting some of the noteworthy historical markers in the field's history. 
The contentious history of the definition of forensic psychology as a broad vs. a narrow field was described, a disagreement that continues to the present. Some sources define forensic psychology broadly, including any subspecialty of psychology in its application of psychology to the law (e.g., the Specialty Guidelines for Forensic Psychology; APA, 2013) whereas others define it narrowly, with attention to the primarily clinical applications of psychology to the law (e.g., the American Psychological Association's definition of forensic psychology as a specialty area of psychology; APA, 2015). Regardless of whether the broad or narrow definition is adopted, the key ethical issue with regard to forensic work is that the psychologist must be or become competent in the area prior to doing forensic work.

The critical differences between therapeutic and forensic roles were reviewed, including the developmental history of the field's recognition of those differences. The literature - and state of the ethics regarding serving in therapeutic and forensic roles - is largely based on two conceptual and theoretical analyses that were published in 1997. These two articles asserted that mental health professionals could serve in separate therapeutic roles or forensic roles, but could not serve ethically in both roles in the same case. This area is ripe for further conceptual (and practical) development, as neither of these articles addresses treatment in forensic contexts and yet the forensic ethical guidelines explicitly allow for treatment in forensic contexts. Some sources have begun to consider the ethical and practical contours of forensic treatment roles, an area that is likely to continue to evolve (see e.g., Neal \& Zelle, in preparation; Zapf \& Roesch, 2011; Zelle \& Neal, in preparation).

Finally, this chapter introduced the uniquely challenging issue of objectivity in forensic contexts. The forensic specialty guidelines stress the importance of striving for objectivity and avoiding "forensic identification" or becoming aligned with an adversarial referral party; 
however, field and experimental research findings demonstrate the insidious effect that working in adversarial forensic contexts has on many psychologist's ability to remain objective. Like the issue of forensic treatment identified above, objectivity and bias in forensic contexts is another area of forensic psychology that is evolving rapidly. Neal and Grisso (2014) asserted that both psychology and the legal system are becoming more aware of the biases that can impact mental health professionals' assessments and conclusions in forensic cases, and that research is needed to identify strategies that can assist forensic mental health professionals in mitigating the effects of bias on their work. In their qualitative interviews with board-certified forensic psychologists, Neal and Brodsky (under review) uncovered several promising bias-correction strategies and discussed the existing evidence for various strategies. The next steps for the field include testing various additional promising strategies and developing an evidence base for and incorporating into training strategies that can mitigate the negative effects of bias in forensic work. 


\section{References}

American Bar Association (1986). American Bar Association Criminal Justice Mental Health Standards. Washington, D.C.: American Bar Association. Retrieved from http://www.americanbar.org/publications/criminal_justice_section_archive/crimjust_stan dards_mentalhealth_toc.html

American Psychological Association. (1992). Ethical principles of psychologists and code of conduct. American Psychologist, 47, 1597-1611.

American Psychological Association. (2010). Ethical principles of psychologists and code of conduct. Available online at www.apa.org/ethics/code/index.aspx

American Psychological Association. (2013). Specialty guidelines for forensic psychology. The American Psychologist, 68, 7-19. doi: 10.1037/a0029889

American Psychological Association (2015, May 14). Recognized specialties and proficiencies: Forensic psychology. Retrieved from http://www.apa.org/ed/graduate/specialize/forensic.aspx

Bartol, C. R., \& Bartol, A. M. (2014). History of forensic psychology. In I.B. Weiner \& R.K. Otto (Eds.), The handbook of forensic psychology, $4^{\text {th }}$ Ed (p. 3-34). Hoboken, NJ: John Wiley \& Sons.

Brigham, J. C. (1999). What is forensic psychology, anyway? Law and Human Behavior, 23, 273-298. doi: 10.1023/A:1022304414537

Committee on Ethical Guidelines for Forensic Psychologists (1991). Specialty guidelines for forensic psychologists. Law and Human Behavior, 15, 655-665. doi:

10.1007/BF01065858 
DeMatteo, D., Edens, J. F., Galloway, M., Cox, J., Toney Smith, S., \& Formon, D. (2014). The role and reliability of the Psychopathy Checklist—Revised in US sexually violent predator evaluations: A case law survey. Law and Human Behavior, 38, 248-255. doi: 10.1037/lhb0000059

Estelle v. Smith, 451 U.S. 454 (1981)

Greenberg, S. A., \& Shuman, D. W. (1997). Irreconcilable conflict between therapeutic and forensic roles. Professional Psychology: Research and Practice, 28, 50-57. doi: 10.1037/0735-7028.28.1.50

Greenberg, S. A., \& Shuman, D. W. (2007). When worlds collide: Therapeutic and forensic roles. Professional Psychology: Research and Practice, 38, 129-132. doi: 10.1037/0735/7028.38.2.129

International Association for Correctional and Forensic Psychology (2010). Standards for psychology services in jails, prisons, correctional facilities, and agencies ( $3^{\text {rd }}$ ed.). Criminal Justice and Behavior, 37, 749-808. doi: 10.1177/0093854810368253

Jaffee v. Redmond, 116 S.Ct. 1923 (1996)

Jenkins v. United States, 307 F.2d 637 (D.C. Cir. 1962) en banc.

Lloyd, C. D., Clark, H. J., \& Forth, A. E. (2010). Psychopathy, expert testimony, and indeterminate sentences: Exploring the relationship between Psychopathy Checklist-Revised testimony and trial outcome in Canada. Legal and Criminological Psychology, 15, 323-339. doi: $10.1348 / 135532509 X 468432$

Muensterberg, H. (1908). On the witness stand: Essays on psychology and crime. New York, NY: McClure. 
Murrie, D.C., Boccaccini, M.T., Guarnera, L.A., \& Rufino K. (2013). Are forensic experts biased by the side that retained them? Psychological Science, 24, 1889-1897. doi:10.1177/0956797613481812.

Murrie, D.C., Boccaccini, M., Johnson, J., \& Janke, C. (2008). Does interrater (dis)agreement on Psychopathy Checklist scores in Sexually Violent Predator trials suggest partisan allegiance in forensic evaluation? Law and Human Behavior, 32, 352-362. doi: 10.1007/s10979-007-9097-5

Murrie, D.C., Boccaccini, M.T., Turner, D.B., Meeks, M., Woods, C., \& Tussey, C. (2009). Rater (dis)agreement on risk assessment measures in sexually violent predator proceedings: Evidence of adversarial allegiance in forensic evaluations? Psychology, Public Policy, and Law, 15, 19-53. doi: 10.1037/a0014897

Neal, T.M.S. \& Brodsky, S.L. (under review). A qualitative investigation of bias and potential correction strategies in forensic mental health evaluations.

Neal, T.M.S. \& Grisso, T. (2014). The cognitive underpinnings of bias in forensic mental health evaluations. Psychology, Public Policy, and Law, 20, 200-211. doi:10.1037/a0035824

Neal, T.M.S., \& Zelle, H. (in preparation). Forensic clinical psychology $\neq$ forensic assessment: Ethical treatment roles for forensic psychology.

Otto, R.K. (1989). Bias and expert testimony of mental health professionals in adversarial proceedings: A preliminary investigation. Behavioral Sciences and the Law, 7, 267-273. doi: $10.1002 / \mathrm{bsl} .2370070210$

Otto, R. K., \& Heilbrun, K. (2002). The practice of forensic psychology: A look toward the future in light of the past. American Psychologist, 57, 5-18. doi: 10.1037/0003066X.57.1.5 
Otto, R.K., \& Ogloff, J.R.P. (2014). Defining forensic psychology. In I.B. Weiner \& R.K. Otto (Eds.), The handbook of forensic psychology, $4^{\text {th }}$ Ed (p. 35-56). Hoboken, NJ: John Wiley \& Sons.

State v. Driver, 88 W.Va. 479, 107 S.E. 189 (1921).

Strasburger, L. H., Gutheil, T. G., \& Brodsky, A. (1997). On wearing two hats: Role conflict in serving as both psychotherapist and expert witness. American Journal of Psychiatry, 154, 448-456. doi:10.11767/ajp/154.4.448

Tapp, J. L. (1976). Psychology and the law: An overture. Annual review of psychology, 27, 359404.

Task Force on the Role of Psychology in the Criminal Justice System (1980). Report of the Task Force on the Role of Psychology in the Criminal Justice System. In J. Monahan (Ed.), Who is the client? The ethics of psychological intervention in the criminal justice system. Washington, DC: American Psychological Association.

Zapf, P. A., \& Roesch, R. (2011). Future directions in the restoration of competency to stand trial. Current Directions in Psychological Science, 20, 43-47. doi: 10.1177/0963721410396798

Zelle, H. \& Neal, T.M.S. (in preparation). Defining the theoretical and practical contours of adjudicative competency restoration treatment.

Zusman, J., \& Simon, J. (1983). Differences in repeated psychiatric examinations of litigants to a lawsuit. American Journal of Psychiatry, 140, 1300-1304. 